\title{
UMA PERSPECTIVA ANTROPOLÓGICA DO FEMINICÍDIO NOS CONTOS DE MARINA COLASANTI
}

\author{
AN ANTHROPOLOGICAL PERSPECTIVE OF FEMINICIDE IN MARINA COLASANTI'S SHORT STORIES
}

\section{RESUMO}

Este artigo apresenta um estudo acerca das regulações do feminicídio nos contos de Marina Colasanti: "Uma questão de educação", da coletânea Contos de amor rasgados (1986), e "Uma ardente história de amor" e "Porém e igualmente", da obra Um espinho de marfim e outras histórias (1999). De acordo com os estudos antropológicos de Vânia Pasinato (2011) e Lia Zanotta Machado (2014), exploramos os sentidos desse crime como uma prática de controle moral e físico da mulher e está atrelado à questão da honra masculina. Entre os corpos femininos que sofrem essa violência, destacamos o assediado e o sacrificado como as imposições do repertório patriarcal conforme as teorias de Elódia Xavier (2007). Por essa perspectiva, defendemos a tese de que a estética da desregulação de gênero, em Colasanti, é construída por recursos literários que promovem a revisão do imaginário masculino e abrem espaço para o questionamento das formas sociais de controle e punição do corpo feminino.

Palavras-chave: Corpo assediado. Violência contra a mulher. Feminicídio.

\begin{abstract}
This article presents a study about the regulations of feminicide in short stories by Marina Colasanti: "Uma questão de educação" in the book Contos de amor rasgados (1986); and "Uma ardente história de amor" and "Porém e igualmente" in the book Um espinho de marfim e outras histórias (1999). According to the anthropological studies by V. Pasinato (2011) e L. Machado (2014), we explore the meanings of this crime as a practice of moral and physical control over women, which is tied to the issue of masculine honor. Among the female bodies that suffer with this violence, we highlight the harassed and the sacrificed ones as the impositions of the patriarchal repertoire according to the theories of Elódia Xavier (2007). From this perspective, we defend the thesis that the aesthetics of gender deregulation in Colasanti is constructed by literary resources which promote the review of the masculine imaginary and open space to the questioning of the social forms of control and punishment of the feminine body.
\end{abstract}

Keywords: Harassed body. Violence against women. Feminicide.

Carlos Magno Gomes

Universidade Federal de Sergipe. Email: calmag@bol.com.br 


\section{Introdução}

A violência contra a mulher no espaço da família se manifesta quando um marido/companheiro impõe normas de controle e/ou punição à sua esposa/ companheira. A recorrência desses crimes como o assédio psicológico, o cárcere privado e as agressões físicas reforçam valores morais que estão centrados em uma contradição social que reconhece a liberdade da mulher ao mesmo tempo em que se veiculam discursos de domínio do corpo feminino como parte do exercício da masculinidade. Tal repertório de gêneros prima pela valorização da força e da virilidade masculina, como marcas da normatização do corpo do homem. No espaço doméstico, a ideia de posse do corpo da mulher e a agressividade masculina dão o ritmo das agressões que, em muitos casos, antecedem o feminicídio'.

Nesse contexto, os crimes de gênero vão além de desvios comportamentais, pois são sustentados por um repertório social que confere inteligibilidade por meio da premissa de que a agressão proporciona respeito aos homens e medo às mulheres. Assim, no espaço familiar, a fantasia de que o corpo da mulher é parte do território masculino é mantida por um repertório que regula esse tipo de violência por diversas maneiras perversas de punição como o feminicídio. Tal crime é usado como uma norma de regulação da identidade feminina e é representada historicamente nas artes com diferentes perspectivas que repetem normas ou questionam formas de controle do corpo feminino. Esse tipo de representação nos convida a uma reflexão de como essa tessitura se realiza na literatura, pois acreditamos que "a literatura responde a um projeto de conhecimento do homem e do mundo” (Compagnon, 2009: 26).

Nos textos literários, o feminicídio é representado como o estopim de um padrão de masculinidade. Por exemplo, na literatura brasileira regionalista, temos exemplos de textos que repetem tais normas como em Menino de engenho (1932), de José Lins do Rêgo. Nessa obra, o personagem-narrador descreve todo seu desespero ao ver a mãe assassinada por seu pai. Todavia, ao relembrar a educação recebida no engenho do avô, ele retoma as lembranças do feminicídio como uma consequência de um homem transtornado e doente. Já na literatura contemporânea, por exemplo, no conto "Venha ver o pôr do sol", da coletânea Antes do baile verde, (1970), Lygia Fagundes Telles nos coloca frente a frente com a mente de um criminoso que arma uma emboscada para sua ex-namorada após ser trocado por outro homem. A produção de Telles tem a peculiaridade de deslocar a identidade masculina por meio de uma estética da desregulação de gênero quando relaciona o repertório machista do criminoso com fantasmas dos valores patriarcais.

No conto de Telles, o desnudamento das engrenagens de violência fica mais explícito, pois o corpo da mulher é punido por questões de gênero e pelo excesso de

1 Neste artigo, vamos trabalhar apenas com a abordagem relacionada ao feminicídio conjugal, aquele praticado pelo companheiro ou ex-companheiro da vítima, mas há diversos casos de feminicídios que são praticados contra mulheres anônimas que externam o ódio misógino praticado por homens violentos como os casos de milhares de mulheres assassinadas na Ciudad Juárez, na década de 1990, no México, de acordo com estudos de Rita Lauro Segado (2005). 
masculinidade exercido na execução do feminicídio. A protagonista, Raquel, tem o corpo sacrificado por um ex-companheiro, Ricardo, que a prende em um cemitério abandonado, depois de planejar uma emboscada como vingança por ter sido trocado por outro. Essa obra traz à tona o repertório social de gênero que condena o corpo da mulher ao sacrifício quando fora do padrão moral patriarcal conforme estudos já publicados sobre essa obra (Gomes, 2014).

Dando sequência a essas reflexões, a partir do diálogo entre texto literário e normas culturais, este artigo abre o debate sobre as regulações e normas que dão sustentação ao feminicídio pela interpretação dos valores morais masculinos descritos nos contos de Marina Colasanti: "Porém e igualmente" e "Uma ardente história de amor", da coletânea Um espinho de marfim e outras histórias (1999), e "Uma questão de educação" da obra Contos de amor rasgados (1986) ${ }^{2}$. Para isso, investigamos os valores sociais da "questão da honra" como justificativa para esse crime, analisando os valores sociais que estruturam o feminicídio: o assédio psicológico, a crise de masculinidade. Esses minicontos desmascaram a estrutura social que condena as mulheres ao sacrifício a partir de valores hegemônicos ao expor o corpo feminino vítima de homens superficiais e mecânicos, mas contraditórios ao fazerem referência a valores culturais próprios do processo civilizatório.

Para esta análise, recorremos a uma base teórica interdisciplinar, respaldada pelos estudos antropológicos. Partiremos das contribuições feministas para a ampliação dos sentidos da violência contra a mulher, levando em conta que a violência de gênero é parte da "violência estrutural reproduzida pelas vias da discriminação nos campos econômico e social” (Segato, 2003: 02). Dentro dos estudos acerca da normatização das regras de gênero, debateremos sobre os valores culturais em torno do feminicídio de acordo com Wânia Pasinato. Pelos aspectos estéticos, retomamos os estudos de Elódia Xavier sobre o corpo feminino na literatura para identificar as marcas do corpo assediado e sacrificado.

\section{A normatização do feminicídio}

Por fazer parte de práticas sociais, a violência contra a mulher precisa ser analisada pelo duplo movimento que a impulsiona: as instâncias das regulações e as operações de poder. Tanto seu campo simbólico, quanto a maneira como ela se repete socialmente são relevantes para uma visão mais ampla dos valores que dão sustentação a esse ato. Judith Butler propõe um deslocamento do imaginário simbólico para as normas culturais generificadas da imposição do poder masculino, visto que a norma é um produto cultural que se mantém pela citação, isto é, "somente pela virtude de seu poder repetido de conferir realidade, é que a norma é constituída como uma norma" (2014: 267).

2 Este texto traz os resultados parciais de uma pesquisa de pós-doutorado desenvolvida junto ao Programa de Pós-Graduação em Antropologia Social da UnB(2016-2018), supervisionada pela Profa. Dra. Lia Zanotta Machado, acerca do feminicídio na literatura brasileira, com financiamento do CNPq. 
Na tradição familiar brasileira, a violência contra a mulher vem de longa data e é parte da cultura patriarcal herdada de uma sociedade excludente e extremamente controladora e disciplinadora. Portanto, estamos diante de um debate que perpassa a questão da violência como parte do imaginário de controle patriarcal para se reestruturar por meio de reflexões acerca dos conceitos de sexo/gênero e poder que confirmam que há "relações desiguais de gênero", quando identificamos o elogio masculino da força e da agressividade (Machado, 2014: 124).

Para desnudar as sutilizas como a violência é regulada, tentamos fugir de categorias homogeneizantes, quando pensamos em causas e contextos e quando buscamos compreender as relações de poder, pois os valores relacionados ao patriarcado também estão se adaptando aos novos contextos, visto que esse repertório de normas culturais "sofreu transformações para garantir sua sobrevivência num mundo em que os papéis sociais de gênero estão mudando em velocidade vertiginosa" (Pasinato, 2011: 237). Como parte de normas coletivas, a violência contra a mulher é regulada por esse imaginário patriarcal, visto que qualquer norma "não é exterior ao seu campo de aplicação", pois "é produzida na produção desse campo" (Butler, 2014: 267). Ao reconhecermos a violência como uma norma, produzida dentro do campo de regulação de gênero, o repertório social, pretendemos fazer uma reflexão sobre os subsídios simbólicos que estão relacionados ao poder masculino na prática do feminicídio.

Além disso, em volta da tênue fronteira entre violência e fantasia, repete-se um discurso de medo das mulheres que passa pela valorização do poder masculino no qual "o temor e medo das mulheres, ou o sentimento de culpa das mulheres foram construídos reciprocamente pela legitimação do poder de gênero instaurado legalmente de controle e castigo dos homens, com a recíproca culpabilização das mulheres" (Machado, 2014: 108). Portanto, a violência de gênero é parte de um campo de luta em que velhos padrões são impostos "de maneira transversal", nos quais o corpo feminino é mantido aprisionado ao desejo do homem (Pasinato, 2011: 239).

Assim, acreditamos que ao questionar a regulação de gênero própria da família patriarcal, a ficção de Marina Colasanti nos proporciona uma densa reflexão acerca das normas que relativizam o feminicídio como um ato de masculinidade. Para esta abordagem, aproximamos forma literária e conteúdo representado, valorizando os elos entre "poética" e "humanidade" como nos sugere Compagnon (2009: 18). Especificamente, tal particularidade de revisar e deslocar o imaginário masculino opressor pode ser identificada como uma marca da "literatura pós-moderna", visto que seus textos são atravessados por “questões ideológicas e políticas”, por priorizar representações caricatas da masculinidade tradicional. Essa literatura em que feminismo e desregulação de gênero se misturam faz parte das estratégias estéticas dos textos pós-modernos conforme nos ensina Linda Hutcheon (1993: 05).

Quanto aos conceitos teóricos sobre a representação da violência na literatura brasileira, destacamos o estudo de Elódia Xavier sobre a representação do corpo feminino, que reconhece o quanto as práticas no interior da família controlam, disciplinam e marginalizam a mulher, "uma vez que as ações corporais são orientadas 
pelos e para os contextos institucionais" (2007: 26). Com base nesse estudo, propomos a identificação de dois tipos de corpo: o "assediado" e o "sacrificado". Esses corpos são regulados por um padrão identitário patriarcal que visa "controlar, fiscalizar a honra e fazer obedecer as mulheres, impondo assim sua vontade quer seja por agressão físico-moral ou apenas moral" (Machado, 2017: 42).

A identificação desses corpos, nos contos de Colasanti, nos dá indícios do quanto sua literatura explora a violência contra a mulher como um intertexto cultural. Assim, os corpos "assediado" e "sacrificado" são representações que condensam tensões sociais e funcionam como roteiros de leitura que tanto nos move para o espaço do texto, como nos coloca frente a frente com valores próprios da violência contra a mulher.

Na continuidade, identificamos as particularidades da estética de desregulação de gênero de Marina Colasanti.

\section{A esposa sacrificada}

Esteticamente, a literatura de Marina Colasanti é marcada por um olhar feminista que desloca valores patriarcais e verdades hegemônicas acerca das relações matrimoniais. Seu universo familiar é um espaço de descentramento e de questionamento das identidades femininas submissas. Seus clássicos contos infantis da coletânea Doze reis e a moça no labirinto do vento (1978) trazem sátiras do imaginário dos contos de fadas com propostas de revisão da história da mulher. Essas narrativas descrevem protagonistas donas de suas histórias, que procuram seus parceiros e se afastam deles quando se sentem oprimidas, pois não aceitam o destino de viver à sombra de um príncipe, rompendo com as regulações próprias do gênero feminino: obediente, submissa e esposa. Assim, esteticamente, a narrativa de Colasanti privilegia o olhar paródico do universo masculino como no clássico "A moça tecelã", dessa mesma coletânea.

Nos contos "Porém igualmente" e "Uma ardente história de amor", da coletânea Um espinho de marfim e outras histórias, identificamos a presença do humor e da ironia como recursos que deslocam a identidade masculina agressora, uma vez que esses minicontos trazem personagens vazios e sem rumo após praticar o feminicídio. As marcas estéticas, quando deslocam normas que naturalizam a violência contra a mulher, têm a particularidade de abrir o texto para os sentidos plurais da interpretação e para uma prática de leitura que atualize os valores morais por trás da representação literária. Assim, estamos preocupados com a identificação de aspectos estéticos que explicitem a moral de macho, relacionada ao padrão patriarcal, aquele que entende o corpo da esposa como uma extensão do marido, que tem 'direito' de posse advindo do contrato de casamento (Machado, 2010: 79).

Esse deslocamento estético é fundamental para ampliarmos os sentidos dos textos literários com arquivo cultural. Tal opção está presente na ironia dos títulos e 
na representação de uma masculinidade pautada pelo culto da força e da virilidade. Nos textos selecionados, a autora abre uma reflexão sobre a brutalidade masculina imposta para manter o controle da esposa e a omissão dos que presenciam as torturas. Em "Porém igualmente", Colasanti aborda a omissão da família e dos vizinhos no caso dos espancamentos que antecedem o feminicídio. A protagonista, D. Eulália, vivia apanhando, mas ninguém se metia na história dela. Para os vizinhos e familiares era vista como "santa" e "anjo" (Colasanti, 2012: 41).

Com a omissão social, a mulher vítima de espancamentos tende a sucumbir diante de tanta violência. No conto não é diferente: "o marido, depois de surrá-la, jogou-a pela janela" (2012: 41). Nesse caso, a violência é praticada como um exercício de força e controle do corpo da mulher. Não há referência a erros que ela tenha cometido. O narrador reforça o silêncio dos que presenciavam os abusos, descrevendo o quanto a omissão também é parte da violência. Nesse conto, o uso do álcool é usado como desculpa para o descontrole masculino, mas o que prevalece é a falta de atitude dos sujeitos que abandonaram a mulher à rotina de espancamentos.

No campo semântico, a autora retoma a metáfora do anjo quando anuncia um feminicídio brutal: "D. Eulália rompeu em asas o voo de sua trajetória” (Colasanti, 2012: 41). Assim, os espancamentos são explorados como parte do repertório que reconhece o corpo sacrificado como o "ponto final em um continuum de terror, que inclui abusos verbais e físicos e uma extensa gama de manifestações de violência e privações a que as mulheres são submetidas ao longo de suas vidas" (Pasinato, 2011: 224). No conto de Colasanti, diante de um quadro de espancamentos contínuos, o feminicídio é anunciado como uma surpresa para todos retomando o paradoxo do título, que é confirmado com o estado de espanto dos vizinhos: "Porém igualmente se surpreenderam" (Colasanti, 2012: 41).

Essa postura de desqualificar a gravidade das agressões físicas e morais do corpo feminino não está restrita a literatura. Lia Zanotta Machado destaca que a violência sofrida dentro de um relacionamento estável ainda é vista como "crimes de bagatela”, pois faz parte da esfera privada. Esse discurso de desqualificação desses delitos é sustentado por uma ideologia que a "defesa da harmonia familiar, da harmonização e da pacificação, transformando os conflitos e violências de gênero como bagatelas" (2017: 44).

Esteticamente, o modelo irônico de Colasanti expõe as contradições do repertório social que aceita uma mulher ser espancada, mas se surpreende com sua morte como reforça os advérbios do título "porém igualmente", que podem ser traduzidos como a desqualificação da gravidade deste crime. Essa postura irônica é condizente com as obras pós-modernas de autoria feminina que primam pela revisão de valores morais mantidos para beneficiar o sujeito masculino (Hutcheon, 1993: o9). Está em jogo, a revisão contra a esposa, pois o corpo feminino é normatizado pela dor e pela humilhação. Trata-se de um corpo disciplinado, ao qual é imposta a submissão do feminino pela força (Xavier, 2007: 59). Além disso, o conto proporciona uma reflexão acerca das contradições sociais identificadas na omissão social diante de casos explícitos de agressão física contra uma mulher. 
No segundo conto selecionado, Colasanti retoma o tema do feminicídio a partir do campo metafórico do uso do corpo da mulher como uma boneca em "Verdadeira história de um amor ardente". O modelo irônico dessa narrativa é costurado do título à cena final do corpo queimado. Com isso, a metáfora da boneca nos ajuda a entender como funciona o abuso do corpo da mulher pela masculinidade excessiva. Tal representação é construída por meio do jogo entre a construção do corpo da boneca e o abuso que ele vai sofrendo até ser descartado: "começou a moldar aquela que preencheria seus desejos" (Colasanti, 2012: 56). Esse corpo de cera maleável se aproxima muito do desejo masculino de total controle do corpo da mulher, alcançado com o uso do corpo feminino dócil, aquele que é "treinado para não ter direitos, para servir", estando sujeito a uma disciplina que orienta obediência e/ou ceder aos desejos do homem (Xavier, 2007: 74).

Essa metáfora do corpo de cera, como uma matriz de docilidade, reproduz um repertório simbólico de total regulação da mulher: "formando e deformando a amada no fluxo do seu prazer" (Colasanti, 2012: 57). Ao colocar em destaque o corpo moldado da esposa, esse conto expõe de forma metafórica valores morais que fazem parte da identidade masculina de acordo com Lia Zanotta Machado, que ressalta que homens violentos têm "controle e posse da mulher, desejo de ter, desejo de não perder, desejo de que as mulheres nada queiram a não ser eles mesmos” (2010: 14).

Assim, nesse contexto de total domínio masculino, o corpo feminino pode ser classificado como "assediado", pois sofre o controle do um companheiro que lhe impõe um misto de terror e abuso como normatização de gênero. Tal violência, simbolicamente assinada pelo desejo de violação tem como pano de fundo "conflitos e estratégias sociais ligadas” aos modos de representação (Moore, 2000: 41).

Logo, a representação da mulher, como boneca, abre o texto literário para o repertório patriarcal de posse do corpo como território da masculinidade. O jogo metonímico do corpo feminino como objeto maculável é normatizado pela noção de docilidade como padrão de submissão da esposa (Xavier, 2007: 58). Além disso, a ironia que atravessa o título do conto "verdadeira história de amor" assusta pela forma fria e racional com que o homem se relaciona com o corpo da boneca. Nesse sentido, a obsessão do homem pelo corpo dócil é abordada como um transtorno comportamental, reproduzindo o desejo de moldura corporal como um obsessão do excesso de masculinidade.

Desse modo, o modelo irônico fica mais explícito na parte final da narrativa, quando o marido resolve se livrar da boneca com um isqueiro. Nesse momento o jogo narrativo retoma a metáfora da execução da esposa ao ressaltar que ele queima o cabelo da companheira: "inflamou a trança da mulher, iluminando o aposento" (Colasanti, 2012: 57). Ao expor a perversidade desse marido, o conto representa o feminicídio como uma opção para o tédio do marido e problematiza o conceito de masculinidade como uma pulsão pelo sacrifício do feminino.

Por essa metáfora do corpo sacrificado, constatamos que a violência que nasce do culto possessivo da virilidade masculina advém do desejo de ter uma esposa moldada ao prazer, todavia descartável conforme o humor do macho: "E, sereno, 
começou a ler à luz do seu passado amor, que queimava lentamente" (Colasanti, 2012: 57). Por essa linha de interpretação, o corpo maculável e descartável está relacionado ao culto do poder masculino. Portanto, o feminicídio é apontado como um crime sustentado por um repertório simbólico de desvalorização do corpo e da liberdade da mulher, (Pasinato, 2011: 232).

Assim, esse conto de Colasanti reproduz um corpo feminino sacrificado como uma extensão do imaginário patriarcal que controla e pune a esposa conforme os desejos do marido. A queima da boneca/esposa reforça o cuidado do texto literário em explorar o intertexto da violência contra a mulher como um recurso estético. Esse modelo literário revisa regulações simbólicas e está relacionado aos limites impostos aos direitos da mulher. Logo, o tom irônico da narrativa pode ser identificado na tentativa de naturalização do corpo da mulher como uma extensão da masculinidade.

Esteticamente, esse modelo irônico pode ser lido pelo fato de esse homem se impor de uma forma unilateral, pois impôs o absurdo do controle da liberdade da esposa. Essa radicalização representacional é artisticamente um construto crítico que denuncia esse tipo de violência e reforça o poder da literatura de nos proporcionar uma escapatória de normas alienantes ou opressoras (Compagnon, 2009: 34). Esse homem raso e mecânico é deslocado pelo tom irônico da narrativa que descreve sua limitação emocional. Nesse caso, Colasanti expõe que o maior problema desse homem mecânico não é sua crise de masculinidade, mas sim o desrespeito pelo direito de liberdade da esposa. Esse modelo artístico faz parte de uma proposta de revisão das normas patriarcais, deslocando o imaginário masculino opressor e a submissão feminina para ressaltar uma estética atravessada por "questões ideológicas e políticas”, quando prioriza representações caricatas machistas (Hutcheon, 1993: 05).

Na sequência, demonstraremos como o modelo paródico de Colasanti vai além do deslocamento do excesso de masculinidade para enfatizar como o machismo se opõe ao processo civilizatório, quando ressalta valores morais por trás do feminicídio conjugal.

\section{A ironia do processo civilizatório}

O modelo estético de desregulação de gênero também está presente nas narrativas que exploram a moral masculina como justificativa para o feminicídio no conto "Uma questão de educação", da obra Contos de amor rasgados. Nesse conto, Colasanti desnuda normas simbólicas e sociais em torno do controle da fidelidade feminina, pois há uma esposa brutalmente decapitada, após ser vista conversando com o amante na porta de casa. Esteticamente, por ser construído por cenas impactantes, temos um olhar particular que encerra um "saber insubstituível" que "desconcerta, incomoda e desorienta", porque é portador de um "apelo à emoção e à empatia” (Compagnon, 2009: 47) 
No terceiro texto selecionado "Uma questão de educação", da coletânea Contos de amor rasgados, Colasanti explora o homicídio macabro e o antropofágico, retomando o modelo irônico de criticar a violência de gênero. $O$ título também traz pistas da referência aos valores morais que serão representados, explorando o feminicídio como parte do ritual da manutenção da moral masculina, pois o marido mata sua esposa, logo após vê-la conversando com outro homem: "Quando ela entrou, decapitou-a com o machado" (Colasanti, 2010: 203). Nessa forma de violência, o corpo da mulher é punido por ter se projetado fora do padrão patriarcal, visto que a significação territorial da corporalidade feminina é fundamentada por normas pertencentes à ordem moral (Segato, 2003: o6). Sua estética traz uma reflexão acerca da contradição do casamento, calcado em valores obsoletos, como a honra, em oposição ao processo civilizatório que ampliou o "debate em torno da desigualdade social entre os sexos", pois não é o marido, "enquanto indivíduo", que concede a liberdade a uma mulher. "Ela se fundamenta na estrutura da própria sociedade" (Elias, 1994: 184).

A negação da falta de domínio do corpo da mulher é exposta pela brutalidade da cena: "Depois recolheu a cabeça e antes que todo o sangue escapasse pelo pescoço truncado, jogou-a na panela. Picou a cebola, os temperos, acrescentou água, e começou a cozinhar a grande sopa” (Colasanti, 2010: 203). Assim como nos contos anteriores, Colasanti vincula a crise de masculinidade ao comportamento patético do personagem masculino. A sequência de ações após a decapitação reforça que se trata de um ritual, que envolvia critérios de como preparar a vingança.

Ao abordar o deslocamento da cultura "da honra familiar e da honra masculina”, o texto revisa comportamentos de fidelidade, que reforçam moralmente, "como contraparte, a submissão e a vergonha das e nas mulheres" (Machado, 2014: 107). Pela lógica patriarcal, a uma mulher não cabe o papel de ser infiel, a regulação de gênero expurga esse comportamento para primar pela posse compulsória do corpo feminino. Assim, o conto retrata uma estrutura de gênero que controla os sombrios territórios do sacrifício feminino como parte dos contratos sociais.

Nesse caso, a decapitação da companheira reforça valores morais que punem e controlam a sexualidade das mulheres. O exagero da cena tenta sintetizar, de forma satírica, o quanto a estrutura de gênero é cega e fascista ao propor o sacrifício da mulher adúltera. Com essa visão, o conto de Colasanti parodia o feminicídio por defesa da honra, opondo-se a um padrão cultural hegemônico de controle e posse do corpo da mulher que só está autorizado a ter desejo pelo marido, pois não pode ter nada para além desse compromisso matrimonial, conforme destaca Lia Machado (2010: 14).

No campo estético, o tom paródico pode ser localizado do título à parte final do conto. Seu roteiro de leitura descreve um ritual macabro sem consumação do ato antropofágico. Tal modelo literário pode ser identificado na rejeição da sopa por causa do fio de cabelo: "Nunca, desde pequeno, suportara a visão de cabelos na comida” (Colasanti, 2010: 203). Guiado por um princípio educacional, o assassino refuga o prato com a cabeça da mulher. Ele não refuga sua sopa antropofágica por ela 
expor o corpo e o rosto da mulher, mas ela confirma a mulher como objeto sacrificial como uma punição metonímica da honra masculina. Sem reconhecimento das regras básicas para uma boa convivência e sem o respeito às normas sociais, o casamento fica vulnerável, pois o "autocontrole" deixa de ser praticado por esse marido, que não respeita hábitos internalizados pela civilização para praticar normas obsoletas de conduta social (Elias, 1994: 106).

O impacto dessa cena nos remete ao questionamento da regulação da honra como um princípio norteador de gênero e brutalidade sustentada por uma questão moral hegemônica que dá sustentação a uma "prática cultural de controle e vingança masculina” e é visto como uma forma de regulação do corpo da mulher (Pasinato, 2011: 232). Assim, no jogo estético de Colasanti, as normas sociais são trapaceadas pelo tom irônico que permite ouvir o grito da mulher sacrificada, reforçando o poder da estética do texto literário (Compagnon, 2009: 37).

Nesse caso, está em jogo o fato de a personagem masculina rejeitar a comida que tem cabelo, todavia ele não teve educação suficiente para propor o diálogo e o entendimento sobre o fim do relacionamento com a esposa. Pelo contrário, o marido opta pelo abatimento da mulher, como se ela fosse um animal que pegou uma doença contagiosa e precisa ser eliminado. Ao expor essa brutalidade, esse conto reforça sua postura feminista explicitando uma normatização traiçoeira para o corpo da mulher, pois a "maior parte dos homicídios de mulheres" que são cometidos em espaços domésticos, "por seus parceiros íntimos ou conhecidos" (Pasinato, 2011: 242).

Dessa forma, a atmosfera macabra desse conto nos remete a uma sociedade de regras aviltantes do desrespeito aos direitos da mulher. Com essa representação repugnante, Colasanti brinca com tais valores, revelando a tirania de um homem que cumpre uma regulação moral de controle de gênero. No plano estético, a visão caricata da delicadeza de um homem que não consegue finalizar seu ritual canibalesco, após decepar a esposa, por uma questão de requinte civilizatório, reforça o quanto as regulações de gênero são contraditórias quando analisamos os princípios punitivos do corpo feminino. O cômico está no fato de haver discrepância entre valores relativos ao respeito à vida e os valores relativos ao requinte ou aos modos da mesa, o abjeto não está no caldo com a cabeça da mulher, mas está no fio de cabelo.

O contraste entre a decapitação da mulher e a rejeição da comida reforça o modelo paródico dessa narrativa que pode ser vista como estratégia de denúncia, pois traz uma paródia de um homem educado que brinca com a justificativa da questão da honra como motivo do feminicídio. Esse deslocamento da brutalidade do crime para o cômico do fio de cabelo na sopa expõe uma estética que desregula valores morais centrados na crise da masculinidade, quando o homem não reconhece a liberdade da companheira para promover valores patriarcais (Gomes, 2016). Essa representação reforça o quanto o sacrifício da mulher ainda faz parte do imaginário masculino como uma saída para a perda da honra. A ambiguidade presente na rejeição da sopa da cabeça da esposa reforça o modelo literário que revisa essas regulações simbólicas que fazem parte da moral hegemônica. 
Esse modelo paródico traz a visão do quanto a violência de gênero é praticada como parte de contratos imaginários. Ela é cometida por maridos em crise com sua honra e valores morais. Nos dois contos em que o feminicídio é descrito, a mulher é punida por homens possessivos e ciumentos, que usam a violência como vingança. São criaturas ameaçadas pelo medo da infidelidade feminina e expõem a fragilidade de um sujeito masculino, traído por questões educacionais. Ao brincar com os valores morais, os contos de Colasanti reforçam a barbárie das regulações morais que desqualificam o corpo feminino e impõem penas fatais.

\section{Considerações finais}

Ao identificarmos, no texto literário de Colasanti, a alternância de modelos estéticos: o irônico e paródico para, questionar a identidade masculina, constatamos o deslocamento de valores morais próprios do patriarcado. Essa técnica narrativa privilegia a representação do feminicídio por uma estética particular que se apropria de um repertório comum da violência para articulá-la de uma posição artística (Compagnon, 2009: 37). Em comum, as narrativas analisadas explicitam o fascismo das regulações de gênero por meio dos deslocamentos irônicos. Seus personagens masculinos repetem normas sociais, mas são carregados de dúvidas e desconfianças que denunciam um sistema de punição impiedoso. Nesse processo representacional, o excesso de masculinidade está articulado por meio da força e brutalidade com que os homens agem em prol de seus valores morais (Machado, 2010).

Esse modelo de desregulação da violência doméstica desloca a postura punitiva dos agressores e descentra a violência simbólica das relações de gênero. Nos contos "Porém e igualmente" e "Uma ardente história de amor", da coletânea Um espinho de marfim e outras histórias, o feminicídio está mais relacionado ao exercício do excesso de masculinidade, presentes na força e na virilidade dos personagens masculinos. Já na narrativa seguinte, "Uma questão de educação", da obra Contos de amor rasgado, o modelo paródico está associado ao riso que a representação do marido vingativo desperta no final do miniconto. Ao representar um marido que refuga da sopa com cabelo, depois da brutalidade de decepar a esposa, o conto expõe a contradição da violência de gênero diante do processo civilizatório.

Tais contos condensam imagens do corpo feminino assediado e sacrificado, pois são normatizados por abusos físicos e psicológicos incorporados à dinâmica do feminicídio no espaço familiar. Nos quatro exemplos, esse crime tem a ver com o excesso de masculinidade e a questão da honra do homem traído. Assim, no contexto patriarcal, o sacrifício da mulher é visto como um ato disciplinador, que resgata a moral do homem, pois o corpo feminino traz as marcas da força e do poder masculino nas relações conjugais e sua execução está simbolicamente naturalizada como resultado da imposição da lógica do macho (Segato, 2003: 03). 
As opções estéticas dos três contos frente aos valores do feminicídio revisa o repertório patriarcal regulado pelo excesso de masculinidade nos dois primeiros casos e pela crise de masculinidade nos segundos. Em comum, há um choque entre valores civilizatórios do casamento e normas punitivas ancestrais como a agressões físicas, violação sexual e imposição da moral do macho. Com essa revisão estética, as "normas abstratas" foram identificadas como formas de controle e punição da mulher, visto que a violência é marcada pela regulação que subordina o feminino ao masculino por meio de processos heterogêneos que tanto "condicionam" como "excedem" os sujeitos que tentam controlar as relações de gênero (Butler, 2014: 272). No texto de Colasanti, essas normas são trapaceadas pelo tom irônico que permite ouvir o grito da mulher sacrificada, reforçando o poder da estética do texto literário (Compagnon, 2009: 37).

A dinâmica desses textos retoma tradições de longa duração que rebaixam os corpos femininos fora dos padrões idealizados, visto que as regulações de gênero "são inventadas e reinventadas" de forma dinâmica para manter os privilégios masculinos (Machado, 2017: 38). Além disso, a literatura de Colasanti expõe a incoerências do feminicídio praticado por um marido que se recusa a aceitar a liberdade da mulher, visto que "o processo civilizador, a despeito da transformação e aumento das limitações que impõe às emoções, é acompanhado permanentemente por tipos de libertação dos mais diversos" (Elias, 1994: 184).

Portanto, os contos de Colasanti contestam discursos sociais einstitucionais que naturalizam a desigualdade de gênero, quando expõem o excesso de masculinidade em contraste com valores civilizatórios nos quatro textos. Essa estratégia literária de expor o absurdo da violência se opõe a discursos institucionais que "produzem a alta tolerância em relação à violência contra as mulheres” (Machado, 2014: 124).

Por fim, destacamos que na ficção de Colasanti, ironia e paródia se confundem para deslocar o poder masculino e desconstruir politicamente representações de gênero contaminadas por "questões ideológicas" hegemônicas, ressaltando uma estética pós-moderna de revisão das representações tradicionais (Hutcheon, 1993: o9). Assim, o modelo paródico de Marina Colasanti reforça a proposta de tradução feminista da literatura pós-moderna que tanto desregula as questões de gênero, por seu olhar paródico da masculinidade, descrita pelo excesso de força e virilidade e pela falta de valores civilizatórios.

\section{Referências bibliográficas}

BUTLER, Judith. (2014). “Desregulando gênero”. Cadernos Pagu. Campinas, Núcleo de Estudos de Gênero, v. 42, p. 249-274.

COLASANTI, Marina. (2010). Contos de amor rasgados. 3. ed. Rio de Janeiro: Record. 
COLASANTI, Marina. (2012). Um espinho de marfim e outras histórias. Porto Alegre: L\&PM.

COMPAGNON, Antoine. (2009). Literatura para quê? Tradução de Laura Taddei Brandini. Belo Horizonte: Editora UFMG.

ELIAS, Norbert. (1994). O processo civilizador. 2. ed. Rio de Janeiro: Jorge Zahar Ed.

GOMES, Carlos Magno. (2014). O femicídio na ficção de autoria feminina brasileira. Estudos Feministas. Florianópolis, UFSC, v. 22, n. 3, p. 781-794.

GOMES, Carlos Magno. (2016) A violência de gênero e a crise de masculinidade. Revista Fórum Identidade, Itabaiana, UFS, v. 21, p. 33-48.

HUTCHEON, Linda. (1993). “La política de la parodia postmoderna”. Traducción del inglés por Desiderio Navarro. Revista Criterios. La Habana, edición especial, p. 187203. Disponível em: http://www.criterios.es/pdf/hutcheonpolitica.pdf. Acesso em 15 de mai. de 2017.

MACHADO, Lia Zanotta. (2010). Feminismo em movimento. São Paulo: Francis.

MACHADO, Lia Zanotta. (2014). "O medo urbano e a violência de gênero". In: MACHADO, Lia Zanotta et al. (Orgs.). A cidade e o medo. Brasília: Verbena/Francis, p. $103-125$.

MACHADO, Lia Zanotta. (2017). "Violência contra as mulheres: diálogos entre feminismo e ciência social”. In DIAS, Alfrancio et al. (orgs) A transversalidade de gênero na produção do conhecimento e nas políticas públicas. Aracaju: Editora IFS, p. 37-54.

MOORE, Henrietta. (200o). "Fantasias de poder e fantasias de identidade: gênero, raça e violência”. Cadernos Pagu. Campinas, Núcleo de Estudos de Gênero, v. 14, p. $13-44$.

PASINATO, Wânia. (2011) "Feminicídios e as mortes de mulheres no Brasil”. Cadernos Pagu, Campinas, Núcleo de Estudos de Gênero, v. 37, p. 219-246.

SEGATO. Rita Laura. (2003). "Las estructuras elementales de la violencia: contrato y status en la etiologia de la violencia”. Série Antropológica. Brasília: Departamento de Antropologia da UnB. 
SEGATO. Rita Laura. (2005). "Território, soberania e crimes de segundo Estado: a escritura nos corpos das mulheres de Ciudad Juárez". Estudos Feministas. Florianópolis, v. 13 , n. 2, p. $265-285$.

XAVIER, Elódia. (2007). Que corpo é esse? O corpo no imaginário feminino. Santa Catarina: Mulheres. 